\title{
Rendimento de grãos de trigo em sistemas de produção com integração lavoura-pecuária, sob plantio direto
}

\author{
Henrique P. Santos ${ }^{1}$, Renato S. Fontaneli ${ }^{1}$, Ricardo L. de Castro², \\ Roberto S. Fontaneli ${ }^{3} \&$ Evandro A. Lampert ${ }^{2}$
}

\footnotetext{
1Embrapa Trigo, Rodovia BR 285, Km 294, CEP 99001-970, Passo Fundo-RS, Brasil. E-mail: hpsantos@cnpt.embrapa.br; renatof@cnpt.embrapa.br. Bolsista de Produtividade em Pesquisa do CNPq

2 Embrapa Trigo, Rodovia BR 285, Km 294, CEP 99001-970, Passo Fundo-RS, Brasil. E-mail: rlcastro@cnpt.embrapa.br; evandro@cnpt.embrapa.br

3 Universidade de Passo Fundo, Faculdade de Agronomia e Medicina Veterinária, Rodovia BR 285, São José, CEP 99052-900, Passo Fundo-RS, Brasil. E-mail: roberto@upf.tche
}

\section{RESUMO}

O objetivo do presente estudo foi avaliar o desempenho de trigo em sistemas de produção com integração lavoura-pecuária (ILP), sob plantio direto. Os tratamentos foram constituídos de cinco sistemas de produção: sistema I (trigo/soja, ervilhaca/ milho e aveia branca/soja); sistema II (trigo/soja, pastagem de aveia preta + ervilhaca/milho e aveia branca/soja); sistema III [pastagens perenes da estação fria - PPF (festuca + trevo branco + trevo vermelho + cornichão)]; sistema IV [pastagens perenes da estação quente PPQ (pensacola + aveia preta + azevém + trevo branco + trevo vermelho + cornichão)] e sistema V (alfafa). 0 delineamento experimental foi em blocos ao acaso, com quatro repetições. 0 trigo cultivado após pastagens perenes de estação quente/milho, mostrou rendimento de grãos mais elevado do que após ervilhaca/milho. 0 trigo cultivado após pastagem de aveia preta + ervilhaca/milho, após PPF/milho e após alfafa/milho, situou-se numa posição intermediária para rendimento de grãos. Não houve diferença na massa do hectolitro, na massa de 1.000 grãos, no número de espigueta por planta, no número de grãos por planta nem na massa de grãos por planta entre os trigos cultivados para os ILP.

Palavras-chave: alfafa, cornichão, festuca, pensacola, trevos

\section{Wheat grain yield in integrated crop-livestock production systems under no-tillage system}

\section{ABSTRACT}

The objective of this study was to assess grain yield of wheat in production systems integrating crop-livestock under no-tillage. The treatments consisted of five production systems: system I (wheat/soybean, common vetch/corn, and wheat oat/soybean); system II (wheat/soybean, black oat (pasture) + common vetch/corn (pasture), and white oat/soybean); system III [perennial cool season pastures (fescue + white clover + red clover + birdsfoot trefoil)]; system IV [perennial warm season pastures (Bahia grass + black oat + rye grass + white clover + red clover + birdsfoot trefoil)]; and system $V$ (alfalfa). A completely randomized block design with four replications was used. Wheat grown after warm-season perennial forages / corn, showed a higher grain yield than after vetch / corn. Wheat grown after black oat + common vetch / corn (pasture), perennial cool-season pasture corn, and after alfalfa/corn, stood in an intermediate position. There were no significant differences in hectoliter weight, 1,000 kernel weight, number of spikes per plant, number of grains per plant, and grain mass per plant among wheats cultivated in crop-livestock integration systems.
\end{abstract}

Key words: alfalfa, Birdsfoot trefoil, tall fescue, Bahia grass, clovers 


\section{Introdução}

De acordo com Balbinot Jr. et al. (2009) existem, no Brasil, várias estratégias básicas que podem ser adotadas como integração lavoura-pecuária, uma das quais é o uso de pastagens perenes por alguns anos, intercalando um ou mais anos com culturas anuais, caso em que as pastagens perenes mais utilizadas no Sudeste do Brasil são as que exibem maior acúmulo de massa no verão como, por exemplo, capim braquiária, capim elefante e capim mombaça. Essa estratégia possui elevada importância para as culturas de verão, tais como soja, milho e arroz irrigado; faltaria incluir, nesses sistemas, culturas produtoras de grãos economicamente viáveis no inverno.

No Sul do Brasil, porém, a integração lavoura-pecuária está sendo divulgada como alternativa às rotações que usam cereais de inverno e para o uso eficiente da terra no período de sucessões de lavoura de verão diversificando a propriedade, diminuindo o risco da lavoura e melhorando o solo (Souza et al., 2009; Fontaneli et al., 2010; Carvalho et al., 2010).

Quanto às propriedades químicas do solo e como observado no sistema plantio direto, o pastejo pode trazer melhoria à fertilidade do solo em razão do acúmulo de matéria orgânica, da alteração na ciclagem de nutrientes (Flores et al., 2008; Souza et al., 2009; Balbino et al., 2011), da melhoria na eficiência do uso de fertilizantes e da capacidade de absorção de nutrientes (Carvalho et., 2010; Conte et al., 2011). No trabalho desenvolvido por Santos et al. (2011b) observouse na maioria das camadas e dos sistemas de produção com integração lavoura-pecuária, que o teor de matéria orgânica do solo foi igual ou superior ao valor registrado quatro anos antes indicando que o uso do sistema plantio direto pode contribuir para o aumento do teor de matéria orgânica do solo e, consequentemente, da sua qualidade.

Na região Sul do Brasil foram iniciados, na década de 1990, experimentos de longa duração envolvendo culturas produtoras de grãos (aveia branca, milho, soja e trigo) em rotação com pastagens anuais de inverno (aveia preta, azevém e ervilhaca) e de verão (milheto) ou com pastagens perenes compostas por alfafa, festuca ou pensacola, consorciadas ao trevo branco, ao trevo vermelho e ao cornichão (Fontaneli et al., 2010; Santos et al., 2001; 2009). Estariam faltando mais trabalhos de longa duração envolvendo pastagens perenes de inverno ou pastagens perenes de verão, por período de três a quatro anos, retornando com lavouras produtoras de grãos anuais de inverno e de verão e avaliando o efeito dessas combinações na fertilidade do solo e no rendimento de grãos das culturas de inverno e de verão.

O presente trabalho teve como objetivo avaliar o efeito de sistemas de produção com integração lavoura-pecuária, sob sistema plantio direto, no rendimento de grãos e em algumas características agronômicas de trigo.

\section{Material e Métodos}

O ensaio foi conduzido no campo experimental da Embrapa Trigo, no município de Passo Fundo, RS, desde 1993, em solo classificado como Latossolo Vermelho Distrófico típico (Streck et al., 2008).

Os tratamentos consistiram de cinco sistemas de produção com integração lavoura-pecuária: sistema I (trigo/soja, ervilhaca/milho e aveia branca/soja); sistema II (trigo/soja, pastagem de aveia preta + ervilhaca/milho e aveia branca/soja); sistema III [pastagens perenes da estação fria (festuca + trevo branco + trevo vermelho + cornichão)]; sistema IV [pastagem perene de estação quente (pensacola) associada a pastagens de inverno (aveia preta + azevém + trevo branco + trevo vermelho + cornichão) no período hibernal]; e sistema $\mathrm{V}$ (alfafa). O trigo foi semeado após aveia branca/soja (Tabela 1). As cultivares de trigo usadas foram Embrapa 16, em 1998, BRS 49, em 1999 e 2000, BRS 179, de 2001 a 2003, BRS Angico, em 2004, BRS Louro, em 2005 e 2006 e a BRS Guamirim, de 2007 a 2011.

A adubação de manutenção foi aplicada de acordo com a indicação para a cultura de trigo e baseada nos resultados da análise de solo (Comissão de Química e Fertilidade do Solo, 2004) de amostras coletadas após a colheita das culturas de verão.

A semeadura, o controle de plantas daninhas e os tratamentos fitossanitários, foram realizados conforme indicação para essa cultura (Comissão Brasileira de Pesquisa de Trigo e Triticale, 2010). A colheita foi efetuada com automotriz especial para

Tabela 1. Sistemas de produção com integração lavoura-pecuária, sob sistema plantio direto. Passo Fundo, RS

\begin{tabular}{|c|c|c|c|c|c|c|c|c|}
\hline \multirow{2}{*}{$\begin{array}{c}\text { Sistema } \\
\text { produção }\end{array}$} & \multicolumn{8}{|c|}{ Ano } \\
\hline & 1996 & 1997 & 1998 & 1999 & $\ldots$ & 2009 & 2010 & 2011 \\
\hline \multirow[t]{3}{*}{ Sistema I } & $T / S$ & $E / M$ & $\mathrm{Ab} / \mathrm{S}$ & $T / S$ & & $E / M$ & $\mathrm{Ab} / \mathrm{S}$ & $\mathrm{T} / \mathrm{S}$ \\
\hline & $\mathrm{E} / \mathrm{M}$ & $\mathrm{Ab} / \mathrm{S}$ & $\mathrm{T} / \mathrm{S}$ & $\mathrm{E} / \mathrm{M}$ & & $\mathrm{Ab} / \mathrm{S}$ & T/S & $\mathrm{E} / \mathrm{M}$ \\
\hline & $\mathrm{Ab} / \mathrm{S}$ & $\mathrm{T} / \mathrm{S}$ & $\mathrm{E} / \mathrm{M}$ & $\mathrm{Ab} / \mathrm{S}$ & & $\mathrm{T} / \mathrm{S}$ & $\mathrm{E} / \mathrm{M}$ & $\mathrm{Ab} / \mathrm{S}$ \\
\hline \multirow[t]{3}{*}{ Sistema II } & $\mathrm{T} / \mathrm{S}$ & $A p+E / M$ & $\mathrm{Ab} / \mathrm{S}$ & $T / S$ & & $A p+E / M$ & $\mathrm{Ab} / \mathrm{S}$ & $T / S$ \\
\hline & $A p+E / M$ & $\mathrm{Ab} / \mathrm{S}$ & $\mathrm{T} / \mathrm{S}$ & $A p+E / M$ & & $\mathrm{Ab} / \mathrm{S}$ & $\mathrm{T} / \mathrm{S}$ & $A p+E / M$ \\
\hline & $\mathrm{Ab} / \mathrm{S}$ & $\mathrm{T} / \mathrm{S}$ & $A p+E / M$ & $\mathrm{Ab} / \mathrm{S}$ & & $T / S$ & $A p+E / M$ & $\mathrm{Ab} / \mathrm{S}$ \\
\hline \multirow[t]{3}{*}{ Sistema III } & PPF/S & $\mathrm{E} / \mathrm{M}$ & $\mathrm{Ab} / \mathrm{S}$ & T/S & & $\mathrm{E} / \mathrm{M}$ & $\mathrm{Ab} / \mathrm{S}$ & $\mathrm{T} / \mathrm{S}$ \\
\hline & PPF/M & $\mathrm{Ab} / \mathrm{S}$ & $\mathrm{T} / \mathrm{S}$ & $\mathrm{E} / \mathrm{M}$ & & $\mathrm{Ab} / \mathrm{S}$ & $\mathrm{T} / \mathrm{S}$ & $\mathrm{E} / \mathrm{M}$ \\
\hline & PPF/S & $T / S$ & $\mathrm{E} / \mathrm{M}$ & $\mathrm{Ab} / \mathrm{S}$ & & $T / S$ & $\mathrm{E} / \mathrm{M}$ & $\mathrm{Ab} / \mathrm{S}$ \\
\hline \multirow[t]{3}{*}{ Sistema IV } & PPQ/S & E/M & $\mathrm{Ab} / \mathrm{S}$ & T/S & & $\mathrm{E} / \mathrm{M}$ & $\mathrm{Ab} / \mathrm{S}$ & $\mathrm{T} / \mathrm{S}$ \\
\hline & PPQ/M & $\mathrm{Ab} / \mathrm{S}$ & $\mathrm{T} / \mathrm{S}$ & $\mathrm{E} / \mathrm{M}$ & & $\mathrm{Ab} / \mathrm{S}$ & $\mathrm{T} / \mathrm{S}$ & $\mathrm{E} / \mathrm{M}$ \\
\hline & $\mathrm{PPQ} / \mathrm{S}$ & T/S & $\mathrm{E} / \mathrm{M}$ & $\mathrm{Ab} / \mathrm{S}$ & & $T / S$ & $\mathrm{E} / \mathrm{M}$ & $\mathrm{Ab} / \mathrm{S}$ \\
\hline \multirow[t]{3}{*}{ Sistema V } & $\mathrm{Al} / \mathrm{S}$ & $\mathrm{E} / \mathrm{M}$ & $\mathrm{Ab} / \mathrm{S}$ & $T / S$ & & $\mathrm{E} / \mathrm{M}$ & $\mathrm{Ab} / \mathrm{S}$ & $T / S$ \\
\hline & $\mathrm{Al} / \mathrm{M}$ & $\mathrm{Ab} / \mathrm{S}$ & $\mathrm{T} / \mathrm{S}$ & $\mathrm{E} / \mathrm{M}$ & & $\mathrm{Ab} / \mathrm{S}$ & $\mathrm{T} / \mathrm{S}$ & $\mathrm{E} / \mathrm{M}$ \\
\hline & $\mathrm{Al} / \mathrm{S}$ & $\mathrm{T} / \mathrm{S}$ & $\mathrm{E} / \mathrm{M}$ & $\mathrm{Ab} / \mathrm{S}$ & & $\mathrm{T} / \mathrm{S}$ & $\mathrm{E} / \mathrm{M}$ & $\mathrm{Ab} / \mathrm{S}$ \\
\hline
\end{tabular}

Sistema I: trigo/soja, ervilhaca/milho e aveia branca/soja; Sistema II: trigo/soja, pastagem de aveia preta + ervilhaca/milho e aveia branca/soja; Sistema III: pastagem perene de estação fria - PPF (festuca + trevo branco + trevo vermelho + cornichão), depois produção de grãos; Sistema IV: pastagem perene de estação quente - PPQ (pensacola) associada a pastagens de inverno (trevo branco + trevo vermelho + cornichão + aveia preta + azevém), depois produção de grãos e Sistema V: alfafa, depois produção de grãos. Ab: aveia branca; Ap: aveia preta; Al: alfafa; E: ervilhaca; M: milho; S: soja; e T: trigo. * No período de 2000 a 2008, houve continuidade dos mesmos sistemas de rotação. 
parcelas experimentais. A área da parcela foi de $20 \mathrm{~m}$ de comprimento por $3 \mathrm{~m}$ de largura $\left(60 \mathrm{~m}^{2}\right)$. O rendimento de grãos de trigo foi determinado a partir da colheita de área de $23,80 \mathrm{~m}^{2}$, ajustando-se o rendimento para umidade de $13 \%$.

O delineamento experimental foi em blocos ao acaso, com quatro repetições. Foi efetuada a análise de variância do rendimento de grãos, da massa do hectolitro, da massa de 1.000 grãos e dos seguintes componentes do rendimento: número de espiguetas por planta, número de grãos por planta e massa de grãos por planta de trigo, dentro de cada ano e na média dos anos, de 1998 a 2011. Considerou-se fixo o efeito do tratamento e o efeito do ano, aleatório. Os parâmetros avaliados foram submetidos à análise de variância, complementada pelo teste de Tukey, a 5\% de probabilidade, com uso do programa estatístico SAS versão 9.2 (SAS, 2008).

\section{Resultados e Discussão}

As médias do rendimento de grãos, da massa do hectolitro, da massa de mil grãos, do número de espiguetas por planta, do número de grãos por planta e da massa de grãos por planta de trigo, de 1998 a 2011, dos cinco sistemas de produção com integração lavoura-pecuária, se encontram nas tabelas de 2 a 7. A análise de variância desses parâmetros mostrou efeitos significativos para anos e sistemas.

Nos anos de 2005, 2006 e 2010 e na média conjunta de 1998 a 2011, houve diferença no rendimento de grãos de trigo entre os sistemas de produção com integração lavourapecuária (Tabela 2). Em 1998, embora tenha sido observada diferença significativa entre as médias de rendimento de grãos pela análise de variância (teste F), esta significância não foi confirmada pelo teste de Tukey, a 5\%, em complementação (Tabela 2).

Em 2005, o trigo cultivado após pastagens de estação quente/milho (sistema IV) apresentou maior valor de rendimento de grãos do que o trigo cultivado após ervilhaca/ milho (sistema I), enquanto o trigo cultivado após pastagem de aveia preta + ervilhaca/milho (sistema II), após pastagens perenes de estação fria/milho (sistema III) e após alfafa/ milho (sistema V) ficou em posição intermediária porém em 2006 o trigo cultivado após ervilhaca/milho (sistema I), após pastagem de aveia preta + ervilhaca/milho (sistema II) e após alfafa/milho (sistema V), mostrou rendimento de grãos mais elevados em comparação com o trigo cultivado após pastagens perenes de estação fria/milho (sistema III) e de estação quente/ milho (sistema IV). Em 2010 o trigo cultivado após pastagens perenes de estação quente/milho (sistema IV) foi superior ao trigo cultivado após alfafa/milho (sistema $\mathrm{V}$ ) para rendimento de grãos, ficando os demais sistemas (I, II e III) em posições intermediárias. Parte desta diferença no rendimento de grãos de trigo, neste ano, pode ser explicada pela massa de 1.000 grãos, que foi maior no trigo cultivado após pastagens perenes de estação quente/milho. Na média conjunta dos anos de 1998 a 2011, o trigo cultivado após pastagens perenes de estação quente/milho (sistema IV) indicou rendimento de grãos superior ao trigo cultivado após ervilhaca/milho (sistema I) e o trigo cultivado após pastagem de aveia preta + ervilhaca/ milho, pastagens perenes de estação fria/milho e após alfafa/ milho, situou-se em posição intermediária para rendimento de grãos.

O rendimento médio de grãos de trigo no período foi de $3.426 \mathrm{~kg} \mathrm{ha}^{-1}$; o maior rendimento médio de grãos de trigo ocorreu no ano de 2010 (5.152 $\left.\mathrm{kg} \mathrm{ha}^{-1}\right)$, enquanto o menor se manifestou no ano de 2001 (1.510 kg ha-1). Constatou-se, em 2001, precipitação de granizo, o que prejudicou o rendimento de grãos de trigo (Tabela 2).

Fontaneli et al. (1998) observaram, estudando sistemas de produção com integração lavoura-pecuária, todavia, com pastagens anuais de estação fria, durante seis anos, sob sistema plantio direto, em Passo Fundo e em região adjacente, diferenças entre os tratamentos. O sistema I (trigo/soja, pastagem de aveia preta/soja e pastagem de aveia preta/soja) sinalizou rendimento de grãos de trigo mais elevado do que o dos demais sistemas de produção. Na avaliação realizada para os atributos químicos e físicos do solo, por Santos et al. (2006) no mesmo experimento, não foram encontradas diferenças

Tabela 2. Rendimento de grãos de trigo em sistemas de produção com integração lavoura-pecuária. Passo Fundo, RS

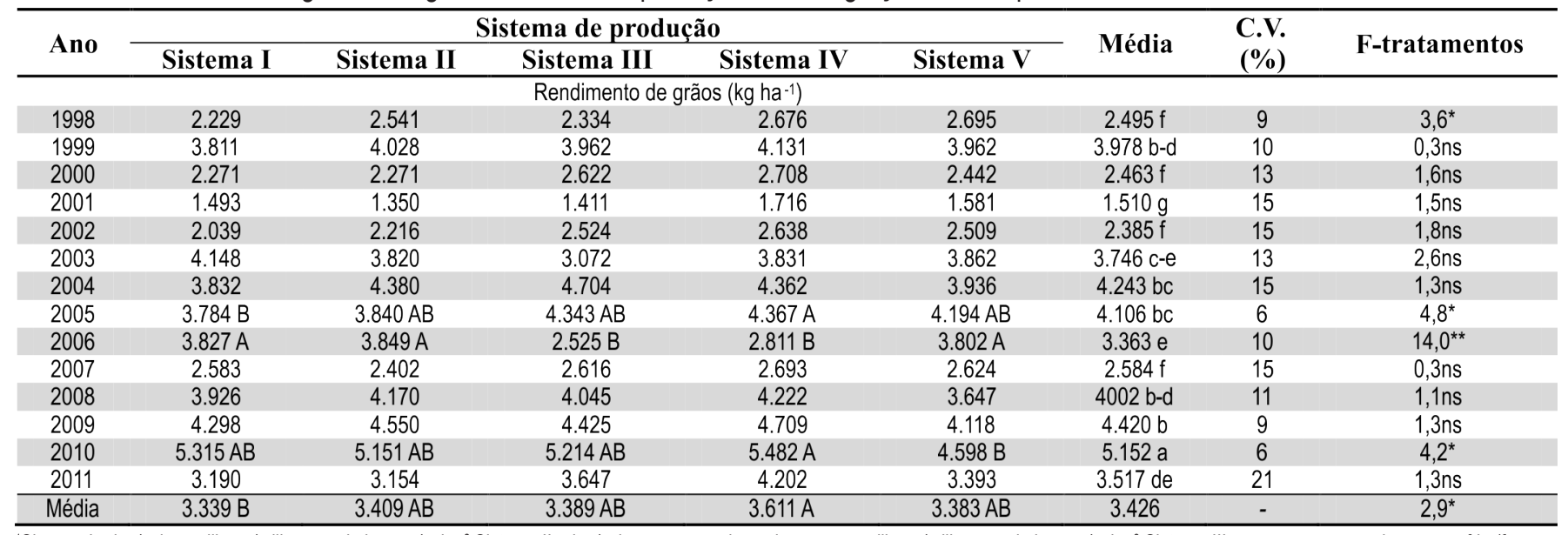

${ }^{1}$ Sistema I: trigo/soja, ervilhaca/milho e aveia branca/soja; ${ }^{2}$ Sistema II: trigo/soja, pastagem de aveia preta + ervilhaca/milho e aveia branca/soja; ${ }^{3}$ Sistema III: pastagem perene de estação fria (festuca + trevos + cornichão), depois produção de grãos; ${ }^{4}$ Sistema IV: pastagem perene de estação quente (pensacola + trevos + cornichão + aveia preta + azevém), depois produção de grãos, $\mathrm{e}^{5}$ Sistema V: alfafa, depois produção de grãos.

Médias seguidas de mesma letra minúscula na vertical e maiúscula na horizontal, não apresentam diferenças significativas a nível de $5 \%$ de probabilidade, pelo teste de Tukey. ns: não significativo; *: nível de significância de $5 \%$; e ** nível de significância de $1 \%$. 
relevantes entre os sistemas de produção com integração lavoura-pecuária.

No trabalho desenvolvido por Santos et al. (2011a), com sistemas de produção com integração lavoura-pecuária, embora com pastagem anual e com cereais de inverno de duplo propósito, durante seis anos, sob sistema plantio direto, foram constatadas diferenças entre os tratamentos. Os sistemas II (trigo/soja e pastagem de aveia preta/milho: $2.614 \mathrm{~kg} \mathrm{ha}^{-1}$ ), III (trigo/soja e pastagem de aveia preta/soja: $2.721 \mathrm{~kg} \mathrm{ha}^{-1}$ ), IV (trigo/soja e ervilha/milho: $2.653 \mathrm{~kg} \mathrm{ha}^{-1}$ ) e V (trigo/soja, triticale de duplo propósito/soja e ervilhaca/soja: $2.743 \mathrm{~kg}$ $\left.\mathrm{ha}^{-1}\right)$ proporcionaram maior rendimento de grãos de trigo em comparação com o sistema VI (trigo/soja, aveia branca de duplo propósito/soja e trigo de duplo propósito/soja: $2.394 \mathrm{~kg} \mathrm{ha}^{-1}$ ). O trigo cultivado no sistema I (trigo/soja e ervilhaca/milho: $2.585 \mathrm{~kg} \mathrm{ha}^{-1}$ ), situou-se numa posição intermediária para rendimento de grãos. Não houve diferenças no rendimento de grãos entre os trigos cultivados para produção de grãos e para duplo propósito. Neste mesmo experimento e na avaliação de 2003, o teor de matéria orgânica do solo foi maior em todas as camadas e em todos os sistemas de produção com integração lavoura-pecuária, do que o encontrado na época da instalação do experimento, em 1995 (Santos et al., 2009); no entanto, entre os sistemas de produção com integração lavoura-pecuária não foram constatadas, em todas as camadas amostradas, diferenças entre os teores de matéria orgânica do solo, mas se verificaram diferenças no teor de matéria orgânica do solo entre todas as camadas amostradas dos sistemas de produção com integração lavoura-pecuária; o teor de matéria orgânica do solo foi decrescente da camada superficial para as camadas mais profundas.

$\mathrm{Na}$ análise conjunta de 1998 a 2000, Fontaneli \& Santos (2003) observaram maior diferença no rendimento de grãos de trigo neste mesmo experimento, resultante de pequenas diferenças acumuladas nos primeiros anos avaliados no trigo cultivado após pastagens perenes de estação quente/milho (3.172 $\left.\mathrm{kg} \mathrm{ha}^{-1}\right)$ e após alfafa/milho (3.033 $\left.\mathrm{kg} \mathrm{ha}^{-1}\right)$, em relação ao trigo cultivado após ervilhaca/milho $\left(2.770 \mathrm{~kg} \mathrm{ha}^{-1}\right)$. O trigo cultivado após pastagem de aveia preta + ervilhaca/milho (2.947 $\left.\mathrm{kg} \mathrm{ha}^{-1}\right)$ e após pastagens perenes de estação fria/milho $\left(2.973 \mathrm{~kg} \mathrm{ha}^{-1}\right)$, se manteve numa posição intermediária para rendimento de grãos.

$\mathrm{Na}$ avaliação dos parâmetros de fertilidade do solo na área experimental, realizada em maio de 1998 (Santos et al., 2001), em quatro camadas $(0-5 \mathrm{~cm}, 5-10 \mathrm{~cm}, 10-15 \mathrm{~cm}$ e $15-20 \mathrm{~cm}$ de profundidade), houve diferenças em algumas camadas amostradas para os teores de matéria orgânica do solo. O sistema IV, formado por pastagens perenes de estação quente, apresentou teor de matéria orgânica do solo $\left(37 \mathrm{~g} \mathrm{~kg}^{-1}\right)$ maior que o dos sistemas, somente para produção de grãos (sistema I: $30 \mathrm{~g} \mathrm{~kg}^{-1}$ ) e pastagem anual de estação fria (sistema II: $28 \mathrm{~g}$ $\mathrm{kg}^{-1}$ ), na camada de $0-5 \mathrm{~cm}$. Nesta mesma camada os sistemas com pastagens perenes de estação fria (sistema III: $33 \mathrm{~g} \mathrm{~kg}$ $\left.{ }^{1}\right)$ e alfafa (sistema $\mathrm{V}: 32 \mathrm{~g} \mathrm{~kg}^{-1}$ ) mostraram valor de matéria orgânica do solo superior ao do sistema II. Esta diferença entre os sistemas de produção com integração lavoura-pecuária pode ser explicada, em parte, pela presença de leguminosas perenes para pastejo (alfafa, cornichão, trevo branco e trevo vermelho) nos sistemas IV e V, em comparação com os sistemas I (trigo/ soja, ervilhaca/milho e aveia branca/soja) e II (trigo/soja, pastagem de aveia preta + ervilhaca/milho e aveia branca/ soja). O uso de leguminosas visando à ciclagem de nutrientes, ao aumento do teor de $\mathrm{N}$ dos sistemas de produção e à elevação da matéria orgânica do solo, tem sido uma estratégia para se atingir produção sustentável (Balbinot Jr. et al., 2009; Calegari et al., 2008 Boddey et al., 2010).

$\mathrm{Na}$ avaliação dos atributos químicos realizada neste mesmo experimento, em 2000, 2001 e 2005, não foram observadas diferenças entre os sistemas de produção com integração lavoura-pecuária para o teor de matéria orgânica do solo (Santos et al., 2011b) todavia, o teor de matéria orgânica do solo aumentou entre os anos de 2000 e 2002, em todas as camadas amostradas; nesse período de estudo os resultados de rendimento de grãos de trigo podem estar relacionados aos teores de matéria orgânica do solo.

Em trabalho desenvolvido com sistemas de manejo de solo após cinco anos, Flores et al. (2008) verificaram que o teor de matéria orgânica do solo foi maior na pastagem de aveia preta + ervilhaca $\left(62 \mathrm{~g} \mathrm{~kg}^{-1}\right)$ e na floresta subtropical $\left(47 \mathrm{~g} \mathrm{~kg}^{-1}\right)$ em relação ao sistema plantio direto $\left(23 \mathrm{~g} \mathrm{~kg}^{-1}\right)$ e ao preparo convencional de solo com arado de discos mais grade (20 g $\mathrm{kg}^{-1}$ ), na camada de $0-5 \mathrm{~cm}$; esses autores não encontraram diferenças para o rendimento de grãos de milho.

Segundo vários autores, sistemas de produção com integração lavoura-pecuária têm aumentado o rendimento de grãos de algumas espécies (milho e soja) ao melhorar as propriedades químicas, físicas e biológicas do solo (Tracy \& Zhang, 2008; Balbinot Jr. et al., 2009; Macedo, 2009; Conte et al., 2011). De acordo com Vilela et al. (2003) as pastagens têm, de modo geral, a capacidade de manter ou aumentar o teor de matéria orgânica do solo, em relação aos cultivos anuais mas somente para a produção de grãos, em virtude da grande quantidade de biomassa e pelo sistema radicular extenso, em constante renovação (Souza et al., 2009; Silva et al., 2011). Os trabalhos relatados acima foram realizados com pastagens perenes de estação quente (Braquiárias) juntamente com a cultura de milho ou de pastagens anuais (aveia preta e azevém) e depois a cultura de soja; todavia, na análise conjunta de 2003 a 2009 (Fontaneli et al., 2010), os autores não constataram, neste mesmo experimento, diferenças no rendimento de grãos de trigo entre os sistemas de produção com integração lavoura-pecuária; neste período de avaliação a diferença acumulada no rendimento de grãos de trigo entre os tratamentos foi relativamente pequena. Até o presente momento não foi encontrado nenhum artigo relatando cultivo de pastagens perenes de estação fria ou de pastagens de estação quente e posteriormente cultivo de trigo para rendimento de grãos, a não ser os de Fontaneli \& Santos (2003) e Fontaneli et al. (2010).

Em 2006 ocorreu diferença na massa do hectolitro de trigo entre os sistemas de produção com integração lavoura-pecuária (Tabela 3). O trigo cultivado após pastagem de aveia preta + ervilhaca/milho (sistema II) e após alfafa/milho (sistema V) mostrou massa do hectolitro maior do que após pastagens perenes de estação fria/milho (sistema III). Na média conjunta dos dados, não houve diferença entre os sistemas de produção 
com integração lavoura-pecuária para massa do hectolitro de trigo; resultados semelhantes para massa do hectolitro foram encontrados por Santos et al. (2011a), trabalhando com sistema de produção de trigo com integração lavoura-pecuária; a massa média do hectolitro de trigo foi de $75 \mathrm{~kg} \mathrm{hl}^{-1}$.

Em 2010 o trigo expressou melhor seu potencial de rendimento de grãos em virtude das condições climáticas terem sido favoráveis ao desenvolvimento da cultura; deve-se ser levar, em consideração que, durante este período de estudo, foram utilizadas seis diferentes cultivares de trigo; em alguns anos a massa do hectolitro se manteve superior ou próxima do padrão (78) requerido para comercialização da cultura do trigo (Tabela 3).

Nos anos 2002, 2005 e 2010, constatou-se diferença na massa de 1.000 grãos de trigo entre os sistemas de produção com integração lavoura-pecuária (Tabela 4). Em 2002 o trigo cultivado após pastagens perenes de estação fria/milho (sistema III) apresentou massa de 1.000 grãos mais elevado do que o trigo cultivado após ervilhaca/milho (sistema I). Em 2005 se destacaram, para massa de 1.000 grãos, os sistemas com o trigo cultivado após ervilhaca/milho (sistema I) e após pastagens perenes de estação fria/milho (sistema III), em relação ao trigo cultivado após pastagem de aveia preta + ervilhaca/milho (sistema II). Em 2010, embora a análise de variância tenha indicado diferença significativa (pelo teste $\mathrm{F}$ ) entre as médias de massa de 1.000 grãos, esta significância não foi confirmada na complementação pelo teste de Tukey, a 5\% (Tabela 4). Nos anos 2010 e 2011 foram obtidos os valores mais elevados de massa de 1.000 grãos, em comparação com os demais anos estudados, período de estudo em que não houve diferenças entre os sistemas de produção com integração lavoura-pecuária para as médias de massa de 1.000 grãos de trigo; resultados similares foram obtidos para massa de 1.000 grãos de trigo, por Santos et al. (2011a), pesquisando sistema de produção com integração lavoura-pecuária; enfim, a massa média de 1.000 grãos de trigo foi de $34 \mathrm{~g}$.

Tabela 3. Massa do hectolitro de trigo em sistemas de produção com integração lavoura-pecuária. Passo Fundo, RS

\begin{tabular}{|c|c|c|c|c|c|c|c|c|}
\hline \multirow{2}{*}{ Ano } & \multicolumn{5}{|c|}{ Sistema de produção } & \multirow{2}{*}{ Média } & \multirow{2}{*}{$\begin{array}{l}\text { C.V. } \\
(\%)\end{array}$} & \multirow{2}{*}{ F-tratamentos } \\
\hline & Sistema I & Sistema II & Sistema III & Sistema IV & Sistema V & & & \\
\hline \multicolumn{9}{|c|}{ Massa do hectolitro $\left(\mathrm{kg} \mathrm{hl}^{-1}\right)$} \\
\hline 1998 & 73 & 74 & 73 & 74 & 73 & $73 \mathrm{de}$ & 2 & $0,4 \mathrm{~ns}$ \\
\hline 1999 & 75 & 75 & 76 & 75 & 76 & $75 b-d$ & 1 & $2,3 n s$ \\
\hline 2000 & 68 & 68 & 68 & 68 & 67 & $68 \mathrm{f}$ & 2 & $0,8 \mathrm{~ns}$ \\
\hline 2001 & 75 & 73 & 74 & 74 & 74 & $74 c-e$ & 2 & $0,3 \mathrm{~ns}$ \\
\hline 2002 & 75 & 75 & 75 & 75 & 76 & 75 b-e & 3 & $0,4 \mathrm{~ns}$ \\
\hline 2003 & 80 & 79 & 76 & 79 & 81 & $79 a$ & 4 & $1,2 \mathrm{~ns}$ \\
\hline 2004 & 79 & 81 & 80 & 79 & 77 & $79 a$ & 5 & $0,7 \mathrm{~ns}$ \\
\hline 2005 & 75 & 74 & 75 & 75 & 74 & 74 c-e & 3 & $0,2 \mathrm{~ns}$ \\
\hline 2006 & $76 \mathrm{AB}$ & $77 \mathrm{~A}$ & $71 \mathrm{~B}$ & $74 A B$ & $77 \mathrm{~A}$ & $75 \mathrm{~b}-\mathrm{e}$ & 3 & $4,8^{*}$ \\
\hline 2007 & 70 & 69 & 70 & 70 & 71 & $70 \mathrm{f}$ & 2 & $2,0 \mathrm{~ns}$ \\
\hline 2008 & 75 & 76 & 77 & 76 & 77 & $76 \mathrm{bc}$ & 2 & $1,1 \mathrm{~ns}$ \\
\hline 2009 & 73 & 73 & 73 & 73 & 73 & $73 \mathrm{e}$ & 2 & $0,1 \mathrm{~ns}$ \\
\hline 2010 & 79 & 78 & 80 & 80 & 79 & $79 a$ & 3 & $0,4 \mathrm{~ns}$ \\
\hline 2011 & 76 & 76 & 78 & 78 & 78 & $77 \mathrm{ab}$ & 3 & $0,9 \mathrm{~ns}$ \\
\hline Média & 75 & 75 & 75 & 75 & 75 & 75 & - & $0,7 \mathrm{~ns}$ \\
\hline \multicolumn{9}{|c|}{$\begin{array}{l}\text { ISistema I: trigo/soja, ervilhaca/milho e aveia branca/soja; }{ }^{2} \text { Sistema II: trigo/soja, pastagem de aveia preta + ervilhaca/milho e aveia branca/soja; }{ }^{3} \text { Sistema III: pastagem perene de estação fria (festuc } \\
\text { + trevos + cornichão), depois produção de grãos; }{ }^{4} \text { Sistema IV: pastagem perene de estação quente (pensacola + trevos + cornichão + aveia preta + azevém), depois produção de grãos, } e^{5} \text { Sistema } \\
\text { e alfafa, depois produção de grãos. }\end{array}$} \\
\hline
\end{tabular}

Tabela 4. Massa de 1.000 grãos de trigo em sistemas de produção com integração lavoura-pecuária. Passo Fundo, RS

\begin{tabular}{|c|c|c|c|c|c|c|c|c|}
\hline \multirow{2}{*}{ Ano } & \multicolumn{5}{|c|}{ Sistema de produção } & \multirow{2}{*}{ Média } & \multirow{2}{*}{$\begin{array}{l}\text { C.V. } \\
(\%)\end{array}$} & \multirow{2}{*}{ F-tratamentos } \\
\hline & Sistema I & Sistema II & Sistema III & Sistema IV & Sistema V & & & \\
\hline \multicolumn{9}{|c|}{ Massa de 1.000 grãos (g) } \\
\hline 1998 & 31 & 32 & 29 & 31 & 31 & 31 ef & 5 & $2,6 \mathrm{~ns}$ \\
\hline 1999 & 35 & 35 & 36 & 36 & 36 & $35 \mathrm{~cd}$ & 3 & $1,4 \mathrm{~ns}$ \\
\hline 2000 & 28 & 28 & 29 & 28 & 28 & $28 \mathrm{~g}$ & 6 & $0,4 \mathrm{~ns}$ \\
\hline 2001 & 30 & 30 & 30 & 30 & 30 & $30 \mathrm{f}$ & 5 & $0,1 \mathrm{~ns}$ \\
\hline 2002 & $26 \mathrm{~B}$ & $27 \mathrm{AB}$ & $29 \mathrm{~A}$ & $28 \mathrm{AB}$ & $27 \mathrm{AB}$ & $28 \mathrm{~g}$ & 3 & $4,2^{*}$ \\
\hline 2003 & 37 & 38 & 38 & 38 & 36 & $38 \mathrm{~b}$ & 4 & $3,0 \mathrm{~ns}$ \\
\hline 2004 & 31 & 31 & 33 & 33 & 32 & $32 \mathrm{e}$ & 9 & $0,8 \mathrm{~ns}$ \\
\hline 2005 & $35 \mathrm{~A}$ & $33 \mathrm{~B}$ & $35 \mathrm{~A}$ & $34 A B$ & $34 \mathrm{AB}$ & $34 \mathrm{~d}$ & 2 & $3,8^{*}$ \\
\hline 2006 & 29 & 29 & 30 & 30 & 31 & $30 f$ & 4 & $2,1 \mathrm{~ns}$ \\
\hline 2007 & 37 & 37 & 37 & 39 & 36 & $37 \mathrm{bc}$ & 5 & $1,9 \mathrm{~ns}$ \\
\hline 2008 & 29 & 29 & 30 & 29 & 29 & $29 \mathrm{fg}$ & 5 & $0,4 \mathrm{~ns}$ \\
\hline 2009 & 35 & 37 & 35 & 37 & 37 & $36 \mathrm{bc}$ & 4 & $1,5 \mathrm{~ns}$ \\
\hline 2010 & $42 \mathrm{~A}$ & $39 \mathrm{~A}$ & $39 \mathrm{~A}$ & $43 \mathrm{~A}$ & $40 \mathrm{~A}$ & $41 \mathrm{a}$ & 4 & $4,6^{*}$ \\
\hline 2011 & 41 & 41 & 40 & 40 & 41 & $41 a$ & 2 & $1,9 \mathrm{~ns}$ \\
\hline Média & 33 & 33 & 33 & 34 & 33 & 34 & - & $2,1 \mathrm{~ns}$ \\
\hline
\end{tabular}


Tabela 5. Número de espigueta/planta de trigo em sistemas de produção com integração lavoura-pecuária. Passo Fundo, RS

\begin{tabular}{|c|c|c|c|c|c|c|c|c|}
\hline \multirow{2}{*}{ Ano } & \multicolumn{5}{|c|}{ Sistema de produção } & \multirow{2}{*}{ Média } & \multirow{2}{*}{$\begin{array}{l}\text { C.V. } \\
(\%)\end{array}$} & \multirow{2}{*}{ F-tratamentos } \\
\hline & Sistema I & Sistema II & Sistema III & Sistema IV & Sistema V & & & \\
\hline \multicolumn{9}{|c|}{ Número de espigueta/planta } \\
\hline 1998 & 16 & 16 & 16 & 17 & 17 & $16 \mathrm{a}-\mathrm{c}$ & 8 & $0,6 \mathrm{~ns}$ \\
\hline 2000 & 16 & 16 & 16 & 16 & 16 & $16 \mathrm{bc}$ & 5 & $0,4 \mathrm{~ns}$ \\
\hline 2001 & 17 & 17 & 17 & 18 & 18 & $17 a$ & 5 & $2,1 \mathrm{~ns}$ \\
\hline 2002 & 16 & 16 & 17 & 17 & 17 & $17 \mathrm{ab}$ & 4 & $2,6 \mathrm{~ns}$ \\
\hline 2003 & 16 & 16 & 15 & 15 & 16 & $16 \mathrm{~cd}$ & 4 & $1,6 \mathrm{~ns}$ \\
\hline 2006 & 17 & 16 & 16 & 17 & 16 & $16 \mathrm{bc}$ & 7 & $1,1 \mathrm{~ns}$ \\
\hline 2007 & 12 & 12 & 12 & 12 & 12 & $12 \mathrm{~g}$ & 6 & $0,8 \mathrm{~ns}$ \\
\hline 2008 & 15 & 15 & 15 & 15 & 15 & $15 \mathrm{de}$ & 4 & $0,6 \mathrm{~ns}$ \\
\hline 2009 & 12 & 12 & 12 & 12 & 13 & $12 \mathrm{~g}$ & 7 & $0,8 \mathrm{~ns}$ \\
\hline 2010 & 12 & 12 & 12 & 11 & 12 & $12 \mathrm{~g}$ & 5 & $1,9 \mathrm{~ns}$ \\
\hline 2011 & 13 & 14 & 13 & 13 & 14 & $13 \mathrm{f}$ & 5 & $1,5 \mathrm{~ns}$ \\
\hline
\end{tabular}

${ }^{1}$ Sistema I: trigo/soja, ervilhaca/milho e aveia branca/soja; ${ }^{2}$ Sistema II: trigo/soja, pastagem de aveia preta + ervilhaca/milho e aveia branca/soja; ${ }^{3}$ Sistema III: pastagem perene de estação fria (festuca + trevos + cornichão), depois produção de grãos; ${ }^{4}$ Sistema IV: pastagem perene de estação quente (pensacola + trevos + cornichão + aveia preta + azevém), depois produção de grãos, $\mathrm{e}^{5}$ Sistema V: alfafa, depois produção de grãos.

Médias seguidas de mesma letra, minúscula na vertical, não apresentam diferenças significativas a nível de 5 \% de probabilidade, pelo teste de Tukey; ns: não significativo

Tabela 6. Número de grãos/planta de trigo em sistemas de produção com integração lavoura-pecuária. Passo Fundo, RS

\begin{tabular}{|c|c|c|c|c|c|c|c|c|}
\hline \multirow{2}{*}{ Ano } & \multicolumn{5}{|c|}{ Sistema de produção } & \multirow{2}{*}{ Média } & \multirow{2}{*}{$\begin{array}{l}\text { C.V. } \\
(\%)\end{array}$} & \multirow{2}{*}{ F-tratamentos } \\
\hline & Sistema I & Sistema II & Sistema III & Sistema IV & Sistema V & & & \\
\hline 1998 & 32 & 30 & 34 & 36 & 37 & $34 b-d$ & 10 & $2,2 \mathrm{~ns}$ \\
\hline 2000 & 33 & 29 & 27 & 31 & 32 & $30 \mathrm{de}$ & 17 & $1,0 \mathrm{~ns}$ \\
\hline 2001 & 29 & 31 & 26 & 31 & 32 & $30 \mathrm{de}$ & 10 & $2,5 n s$ \\
\hline 2002 & 30 & 31 & 34 & 35 & 37 & $33 b-d$ & 10 & $2,7 \mathrm{~ns}$ \\
\hline 2003 & 32 & 30 & 32 & 32 & 32 & $31 \mathrm{~cd}$ & 8 & $0,5 \mathrm{~ns}$ \\
\hline 2006 & 42 & 37 & 41 & 41 & 34 & $39 a$ & 11 & $2,1 \mathrm{~ns}$ \\
\hline 2007 & 18 & 19 & 21 & 21 & 20 & $20 \mathrm{~g}$ & 26 & $0,2 \mathrm{~ns}$ \\
\hline 2008 & 33 & 38 & 36 & 36 & 35 & $36 a-c$ & 16 & $0,4 \mathrm{~ns}$ \\
\hline 2009 & 25 & 25 & 24 & 20 & 22 & $23 \mathrm{fg}$ & 20 & $0,7 \mathrm{~ns}$ \\
\hline 2010 & 26 & 28 & 27 & 19 & 25 & $25 f$ & 17 & $2,6 \mathrm{~ns}$ \\
\hline 2011 & 32 & 33 & 31 & 32 & 32 & $32 \mathrm{~cd}$ & 10 & $0,2 \mathrm{~ns}$ \\
\hline
\end{tabular}

'Sistema l: trigo/soja, ervilhaca/milho e aveia branca/soja; ${ }^{2}$ Sistema II: trigo/soja, pastagem de aveia preta + ervilhaca/milho e aveia branca/soja; ${ }^{3}$ Sistema III: pastagem perene de estação fria (festuca + trevos + cornichão), depois produção de grãos; ${ }^{4}$ Sistema IV: pastagem perene de estação quente (pensacola + trevos + cornichão + aveia preta + azevém), depois produção de grãos, $\mathrm{e}^{5}$ Sistema V: alfafa, depois produção de grãos.

Médias seguidas de mesma letra, minúscula na vertical, não apresentam diferenças significativas a nível de $5 \%$ de probabilidade, pelo teste de Tukey; ns: não significativo.

Tabela 7. Massa de grãos/planta de trigo em sistemas de produção com integração lavoura-pecuária. Passo Fundo, RS

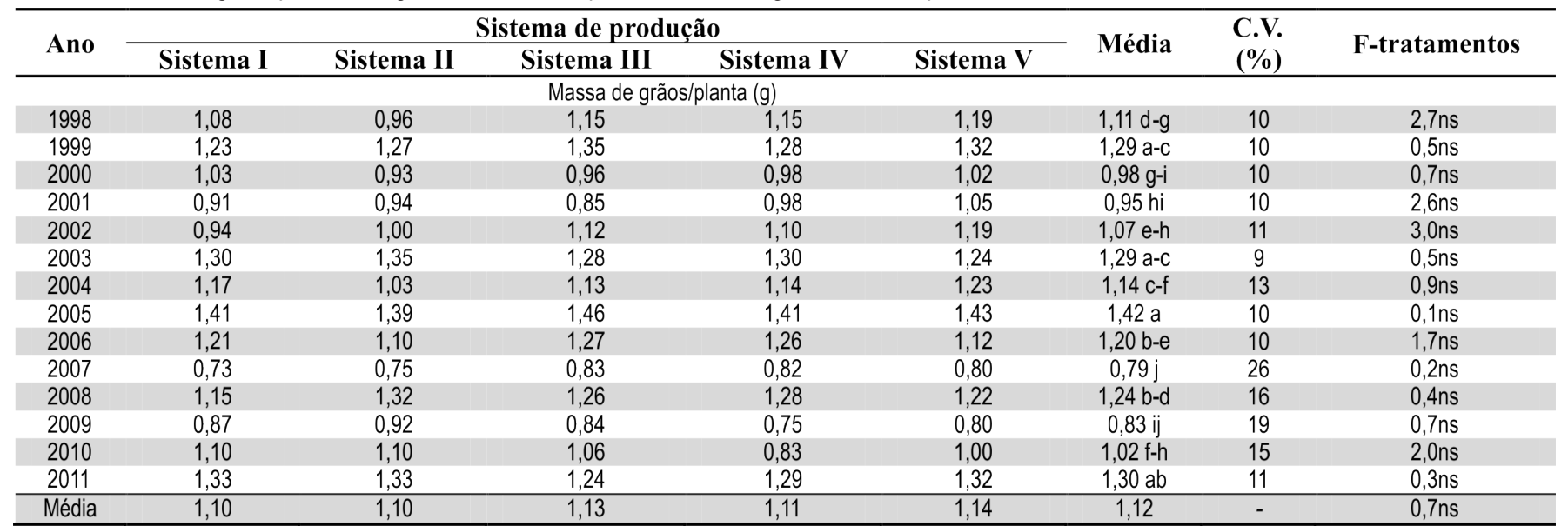

${ }^{1}$ Sistema I: trigo/soja, ervilhaca/milho e aveia branca/soja; ${ }^{2}$ Sistema II: trigo/soja, pastagem de aveia preta + ervilhaca/milho e aveia branca/soja; ${ }^{3}$ Sistema III: pastagem perene de estação fria (festuca + trevos + cornichão), depois produção de grãos; ${ }^{4}$ Sistema IV: pastagem perene de estação quente (pensacola + trevos + cornichão + aveia preta + azevém), depois produção de grãos, e ${ }^{5}$ Sistema V: alfafa, depois produção de grãos.

Médias seguidas de mesma letra minúscula na vertical, não apresentam diferenças significativas a nivel de $5 \%$ de probabilidade, pelo teste de Tukey. ns: não significativo. 
Entre os anos avaliados e na média conjunta de 1998 a 2011, não houve diferença quanto aos componentes do rendimento (número de espiguetas por planta, número de grãos por planta e massa de grãos por planta) entre os sistemas de produção com integração lavoura-pecuária (Tabelas 5 a 7) porém se verificou, nos anos 1999, 2001 e 2002, maior número de espiguetas por planta de trigo em relação aos demais anos estudados (Tabela 5). O ano de 2006 foi destaque para número de grãos por planta de trigo (Tabela 6), enquanto o ano de 2005 se destacou para massa de grãos por planta de trigo, em comparação com a maioria dos anos estudados (Tabela 7). É provável que isto tenha ocorrido em razão do trigo ter sido cultivado com intervalo de dois invernos de rotação; resultados semelhantes foram obtidos por Santos et al. (2011a), com trigo cultivado após pastagens anuais de inverno e após cereais de duplo propósito (aveia branca, trigo e triticale). O número médio de espiguetas por planta, o número de grãos por planta e a massa de grãos por planta de trigo, foram de 15, 31 e 1,12 $\mathrm{g}$, respectivamente.

\section{Conclusões}

A cultura de trigo cultivada após pastagens perenes de estação quente (sistema IV) tem mostrado rendimento de grãos maior que após ervilhaca (sistema I).

O trigo cultivado após pastagem de aveia preta + ervilhaca/ milho (sistema II), após pastagens perenes de estação fria/ milho (sistema III) e após alfafa/milho (sistema V), se situou numa posição intermediária para rendimento de grãos.

Não houve diferença na massa do hectolitro, na massa de 1.000 grãos, no número de espigueta por planta, no número de grãos por planta nem na massa de grãos por planta entre os trigos cultivados para os sistemas de produção com integração lavoura-pecuária.

\section{Literatura Citada}

Balbino, L. C.; Cordeiro, L. A. M.; Porfírio-da-Silva, V.; Moraes, A. de; Martínez, G. B.; Alvarenga, R. C.; Kichel, A. N.; Fontaneli, R. S.; Santos, H. P. dos; Franchini, J. C.; Galerani, P. R. Evolução tecnológica e arranjos produtivos de sistemas de integração lavoura-pecuária-floresta no Brasil. Pesquisa Agropecuária Brasileira, v.46, n.10, p.ixii, 2011. <http://dx.doi.org.ez103.periodicos.capes.gov. br/10.1590/S0100-204X2011001000001>.

Balbinot Jr., A. A.; Moraes, A.; Veiga, M.; Pelissari, A.; Dickow, J. Integração lavoura-pecuária: intensificação de uso de áreas agrícolas. Ciência Rural, v.39, n.6, p.1925-1933, 2009. <http://dx.doi.org/10.1590/S010384782009005000106>.

Boddey, R. M.; Jantália, C. A.; Conceição, P. C.; Zanatta, J. A.; Bayer, C.; Mielniczuck, J.; Dieckow, J.; Santos, H. P. dos; Denardin, J. E.; Aita, C.; Giacomini, S. J.; Alves, B. J. R.; Urquiaga, S. Carbon accumulation at depth in Ferralsols under zero-till subtropical agriculture. Global Change Biology, v.16, n.2, p.784-795, 2010. <http://dx.doi.org/10 $.1111 / \mathrm{j} .1365-2486.2009 .02020>$.
Calegari, A.; Hargrove, W. L.; Rheinheimer, D. S.; Ralisch, R.; Tessier, D.; Tourdonnet, S.; Guimarães, M. F. Impact of long-term no-tillage and cropping system management. Agronomy Journal, v.100, n.4, p.1.013-1.019, 2008. $<$ http://dx.doi.org/10.2134/agroj2007.0121>.

Carvalho, J. L. N.; Avanzi, J. C.; Silva, L. M. N.; Mello, C. R. de; Cerri, C. E. P. Potencial de sequestro de carbono em diferentes biomas do Brasil. Revista Brasileira de Ciência do Solo, v.34, p.277-289, 2010. <http://dx.doi.org/10.1590/ S0100-0683201000020000>.

Comissão Brasileira de Pesquisa de Trigo e Triticale. Informações Técnicas para trigo e triticale - Safra 2011. Cascavel: COODETEC, 2010. 170p.

Comissão de Química e Fertilidade do Solo. Sociedade Brasileira de Ciência do Solo Manual de adubação e de calagem para os estados do Rio Grande do Sul e de Santa Catarina. 10.ed. Porto Alegre: CQFS/SBSC/NRS, 2004. 400p.

Conte, O.; Flores, J. P. C.; Cassol, L. C.; Anghinoni, I.; Carvalho, P. C. de F.; Levien, R.; Wesp, C. de L. Evolução de atributos físicos de solo em sistemas de integração lavourapecuária. Pesquisa Agropecuária Brasileira, v.46, n.10, p.1301-1309, 2011. <http://dx.doi.org.ez103.periodicos. capes.gov.br/10.1590/S0100-204X2011001000026>.

Flores, J. P. C.; Cassol, L. C.; Anghinoni, I.; Carvalho, P. C. de F. Atributos químicos do solo em função da aplicação superficial de calcário em sistema de integração lavoura pecuária submetido a pressões de pastejo em plantio direto. Revista Brasileira de Ciência do Solo, v.32, n.6, p.2385-2396, 2008. <http://dx.doi.org/10.1590/S0100$06832008000600017>$.

Fontaneli, R. S.; Santos, H. P. dos. Rendimento de grãos de trigo em sistemas de produção envolvendo pastagens anuais e perenes, sob plantio direto. Revista Brasileira de Agrociência, v.9, n.4, p.353-356, 2003. <http://www.ufpel. tche.br/faem/agrociencia/v9n4/artigo07.htm>. 05 Jan. 2013.

Fontaneli, R. S.; Santos, H. P. dos; Reis, E. M.; Ambrosi, I. Efeito da rotação de culturas com pastagens anuais de inverno no rendimento de grãos de trigo. Pesquisa Agropecuária Brasileira, v.33, n.10, p.1581-1586, 1998. <https://seer.sct. embrapa.br/index.php/pab/article/view/4999>.

Fontaneli, R. S.; Santos, H. P. dos; Spera, S. T.; Vargas, L. Efeito de sistemas de produção com integração lavourapecuária (SPILP), no rendimento de grãos de trigo, sob plantio direto. In: Embrapa Trigo (Ed.). Trigo: resultados de pesquisa - safra 2009. Passo Fundo: Embrapa Trigo, 2010. p.57-69. (Documentos, 96).

Macedo, M. C. M. Integração lavoura pecuária o estado da arte e inovações tecnológicas Revista Brasileira de Zootecnia, v.38, n.especial, p.133-146, 2009. <http:// dx.doi.org/10.1590/S1516-35982009001300015>.

Santos, H. P. dos; Fontaneli, R. S.; Caierão, E.; Spera, S. T.; Vargas, L. Desempenho agronômico de trigo cultivado para grãos e duplo propósito em sistemas de integração lavoura-pecuária. Pesquisa Agropecuária Brasileira, v.46, n.10, p.1206-1213, out. 2011a. <http://dx.doi. org.ez103.periodicos.capes.gov.br/10.1590/S0100204X2011001000013>. 
Santos, H. P. dos; Fontaneli, R. S.; Spera, S. T.; Dreon, G. Fertilidade e teor de matéria orgânica do solo em sistemas de produção com integração lavoura e pecuária sob plantio direto. Revista Brasileira de Ciências Agrárias, v.6, n.3, p.474-482, 2011b. <http://dx.doi.org/10.5039/agraria. v6i3a1266>.

Santos, H. P. dos; Fontaneli, R. S.; Spera, S. T.; Tomm. G. O. Efeito de sistemas de produção integração lavoura-pecuária (ILP) sobre a fertilidade do solo. Acta Scientiarum. Agronomy, v.31, n.4, p.719-727, 2009. <http://dx.doi. org/10.4025/actasciagron.v31i4.925>.

Santos, H. P. dos; Fontaneli, R. S.; Tomm, G. O. Efeito de sistemas de produção de grãos e de pastagens sob plantio direto sobre o nível de fertilidade do solo após cinco anos. Revista Brasileira de Ciência do Solo, v.25, n.3, p.645-653, 2001. <http://sbcs.solos.ufv.br/solos/revistas/v25n3a13. pdf>. 05 Jan. 2013.

Santos, H. P. dos; Fontaneli, R. S.; Tomm, G. O.; Denardin, J. E. Atributos físicos e químicos de solo em sistemas de produção de grãos envolvendo pastagens anuais sob plantio direto. Pesquisa Agropecuária Gaúcha, v.12, n.1-2, p.7381, 2006. <http://www.fepagro.rs.gov.br/upload/2012022 3164716vol_12_n_1_e_2_art_10.pdf $>05$ Jan. 2013.

SAS Institute. SAS system for microsoft windows version 9.2. Cary: SAS, 2008. CD Rom.
Silva, R. F. da; Guimarães, M. de F.; Aquino, A. M. de; Mercante, F. M. Análise conjunta de atributos físicos e biológicos do solo sob sistema de integração lavourapecuária. Pesquisa Agropecuária Brasileira, v.46, n.10, p.1277-1283, 2011. <http://dx.doi.org.ez103.periodicos. capes.gov.br/10.1590/S0100- 204X2011001000022>.

Souza, E. D. de; Costa, S. E. V. G. de A.; Anghinoni, I.; Carvalho, P. C. de F.; Andrigueti, M.; Cao, E. Estoques de carbono orgânico e de nitrogênio no solo em sistemas de integração lavoura-pecuária em plantio direto, submetido a intensidade de pastejo. Revista Brasileira de Ciência do Solo, v.33, n.6, p.1829-1836, 2009. <http://dx.doi. org/10.1590/S0100-06832009000600031>.

Streck, E. V.; Kämpf, N.; Dalmolin, R. S. D.; Klamt, E.; Nascimento, P. C. do; Schneider, P.; Giasson, E.; Pinto, L. F. S. Solos do Rio Grande do Sul. 2.ed. Porto Alegre: EMATER/RS, 2008. 222 p.

Tracy, B. F.; Zhang, Y. Soil Compaction, corn yield response, and soil nutrient pool dynamics within and integrated crop-livestock system in Illinois. Crop Science, v.48, n.3, p.1211-1218, 2008. <http://dx.doi.org/10.2135/ cropsci2007.07.0390>.

Vilela, L.; Macedo, M. C. M.; Martha Jr., G. B.; Kluthcouski, J. Benefícios da integração lavoura-pecuária. In: Kluthcouski, J.; Stone, L. F.; Aidar, H. (Eds.). Integração lavoura-pecuária. Santo Antônio de Goiás: Embrapa Arroz e Feijão, 2003. p.145-170. 